Благодаря уникальной способности атомов углерода соединяться друг с другом и образовывать длинные молекулы, включающие в качестве заместителей и другие элементы, возникло огромное множество органических соединений. Но, даже соединяясь только сам с собой, углерод способен порождать огромный набор различных структур с разнообразными свойствами - так называемых аллотропных модификаций [2].

Переход на наноуровень открывает новые уникальные свойства углерода. Оказалось, что атомы углерода способны без участия других элементов образовывать целый набор наноструктур, отличающихся друг от друга, в том числе и размерностью. В их число входят фуллерены, графен, нанотрубки, наноконы и так далее.

Перспективное применение нанотехнологий принесет резкое увеличение стоимости валового внутреннего продукта и значительный экономический эффект в следующих базовых отраслях экономики [3].

В электронике и оптоэлектронике - расширение возможностей радиолокационных систем за счет применения фазированных антенных решеток с малошумящими СВЧ-транзисторами на базе наноструктур и волоконно-оптических линий связи с повышенной пропускной способностью с применением фотоприемников и инжекционных лазеров на структурах с квантовыми точками; усовершенствование тепловизионныхобзорноприцельных систем на основе применения матричных фотоприемных устройств, изготовленных на основе нанотехнологий и отличающихся высоким температурным разрешением; создание мощных экономичных инжекционных лазеров на базе наноструктур для накачки твердотельных лазеров, применяемых в фемтосекундных системах.

В информатике - многократное повышение производительности систем передачи, хранения и обработки информации; создание новых архитектур высокопроизводительных устройств с приближением возможностей вычислительных систем к свойствам объектов живой природы с элементами интеллекта; адаптивное распределение управления функциональными системами, специализированные компоненты которые для достижения цели способны к самообучению и координированным действиям [3].

$$
* * *
$$

1. Вуль А.Я., Соколов В.И. Исследования наноуглерода в России: от фуллеренов к нанотрубкам и наноалмазам/ Российские нанотехнологии, 2007. Т. 3.

2. Pokropivny V.V., Skorokhod V.V. New dimensionality classifications of nanostructures // Physica E, 2008.

3. Кац Е.А. Фуллерены, углеродные нанотрубки и нанокластеры: родословная форм и идей. - М.: ЛКИ, 2008.

\title{
Чжан Р.В. \\ Использование естественных криогенных ресурсов криолитозоны в гидротехническом строительстве
}

Институт мерзлотоведения им П. И. Мельникова СО РАН doi:10.18411/spc-12-04-2018-31

(Россия,Якутск) idsp: 000001:spc-12-04-2018-31

Аннотация
При освоении Сибири и Дальнего Востока России, которая характеризуется
суровыми природно-климатическими и сложными мерзлотно-геологическими
условиями необходимо решение ряда проблем технико-экономического,
экологического и инженерного характера. Остро стоит задача обеспечения
устойчивости гидротехнических сооружений. В статье предложен один из путей


решения этой задачи, а именно использование естественных криогенных ресурсов Земли.

Ключевые слова: криолитозона, криопэг, криогенный ресурс, гидротехническое сооружение, основание, плотина.

Понятие «ресурсы» вобрало в себя большое множество категорий живой и неживой природы, включая экономические и информационные источники [1], [3], [6], [7]. Ресурсный подход в природопользовании криолитозоны сформулировал представление о своеобразном природном ресурсе многолетнемерзлой толщи криогенном ресурсе. Криогенный ресурс литогенной основы с успехом используется в фундаментостроении отдельных сооружений и целых технических систем. Однако многолетнемерзлые грунты, используемые в качестве оснований сооружений в процессе эксплуатации, подвержены антропогенному влиянию и изменению климата на Земле, которое началось с середины прошлого столетия. Эти два фактора направлены на повышение температуры грунтов и как следствие понижение их прочностных свойств. В сложившейся ситуации необходимо принимать меры по сохранению теплового состояния грунтов, обеспечивающих их нормативную несущую способность. В этой связи возникла мысль о создании инновационной технологии по обеспечению устойчивости грунтов, используемых в качестве тела и оснований гидротехнических сооружений, обладающей высоким эколого-экономическим эффектом с использованием криогенных ресурсов криолитозоны.

Криогенные ресурсы есть часть природных ресурсов, и под которыми понимаем [1]: «материальные объекты знания и силь природы, происхождение и развитие которых обусловлено сферой холода (температурой среды ниже нуля), и которые используются или могут быть использованы человеком в качестве предметов или средств производства». Различают искусственные и естественные криогенные ресурсы. Искусственные криогенные ресурсы создаются человеком, естественные криогенные ресурсы - чисто природный продукт и являются «составным элементом холодного географического пространства, ... и распространены во всех трех сферах планета Земля - в атмосфере, литосфере и гидросфере».

К настоящему времени существует единственная классификация криогенных ресурсов [1], в которую наряду с материальными включены энергетические и информационные ресурсы. Последние приобретают важнейшее значение, так как позволяют объединить мировую логистику хозяйственной деятельности на благо народов [6].

Криопэги - это соленые подземные воды и рассолы, имеющие отрицательную температуру, но находящиеся в жидком состоянии. Вода не замерзает при низких температурах в результате высокой (от 50 г/л и выше) минерализации. Первую классификацию природных вод по температурному режиму предложил Н.И. Толстихин [8]. Температура подземных и надмерзлотныхкриопэгов может достигать $-30 \ldots-40^{0} \mathrm{C}$, межмерзлотных $-2 \ldots-12^{0} \mathrm{C}$, подмерзлотных $0 \ldots-5^{\circ} \mathrm{C}[1],[5]$.

Использование естественных криогенных ресурсов - рассолов с отрицательными температурами, залегающих в криолитозоне, для замораживания и понижении температуры грунтов, используемых в качестве оснований в промышленном и гражданском строительстве, была разработана технологическая система [9], на которую получен патент [10].

При разработке полезных ископаемых в криолитозоне вскрываются подземные воды - криопэги (рассолы), мешающие добычным работам в котлованах. Для производства работ «насухо» рассолы перекачивают в специально создаваемые рассолохранилища, образуемые с помощью грунтовых плотин.

Гидроузлы для хранения рассолов в условиях криолитозоны являются специфическими гидротехническими сооружениями. Специфичность их заключается в 
том, что рассолохранилища в процессе эксплуатации приобретают по глубине характерный температурный и гидрохимический режим. Установлено, что придонные слои круглый год имеют высокую концентрацию солей (120-130 г/л) и устойчивую отрицательную температуру в пределах от $-4^{0} \mathrm{C}$ до $-8,3^{0} \mathrm{C}$ [1], [2]. При взаимодействии криопэгов с многолетнемерзлыми породами, лед содержащийся в них растворяется. Породы переходят в новое криогенное состояние, но уже с измененными физикомеханическими свойствами. Особенно изменяются их фильтрационные и прочностные характеристики, которые определяют устойчивость сооружения в целом. В случае потери устойчивости сооружения возникает ряд проблем экологического характера, вплоть до нарушения биоты целых регионов.

На мысль повысить статическую и фильтрационную устойчивость грунтовой плотины с использованием рассолов натолкнули исследования проводимые Институтом мерзлотоведения СО РАН на плотине рассолохранилища, на руч. Тымтайдаах [4].

Накопитель минерализованных вод системы осушения карьера «Мир» находится в 8 км к северо-востоку от г. Мирный Республики Саха (Якутия), в верховьях ручья Тымтайдаах, левого притока реки Малая Ботуобия, впадающей в р. Вилюй. Накопитель является гидротехническим сооружением II класса капитальности, по типу балочный, наливной. Грунтовая плотина, насыпная, каменно-набросная из мергелей и диабазов, с ядром, зубом и понуром из суглинка, таломерзлого типа. Основные проектные параметры плотины: отметка гребня - 327,0 м; максимальная высота - 37,5 м; длина по гребню - 1100,0 м. На рис. 1 и 2 изображены план, общий вид гидроузла и сечение плотины накопителя рассолов.

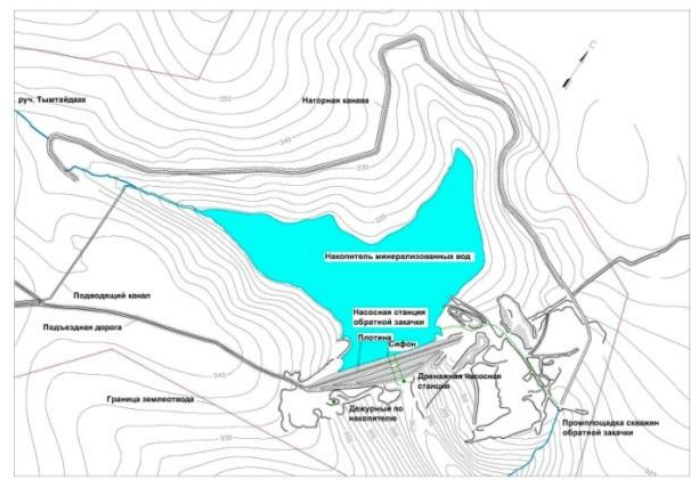

$a$

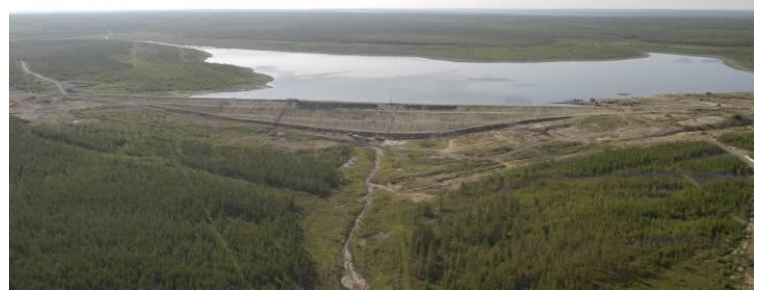

$\sigma$

Рис.1. План (а) и общий вид гидроузла на руч. Тымтайдаaх (б)

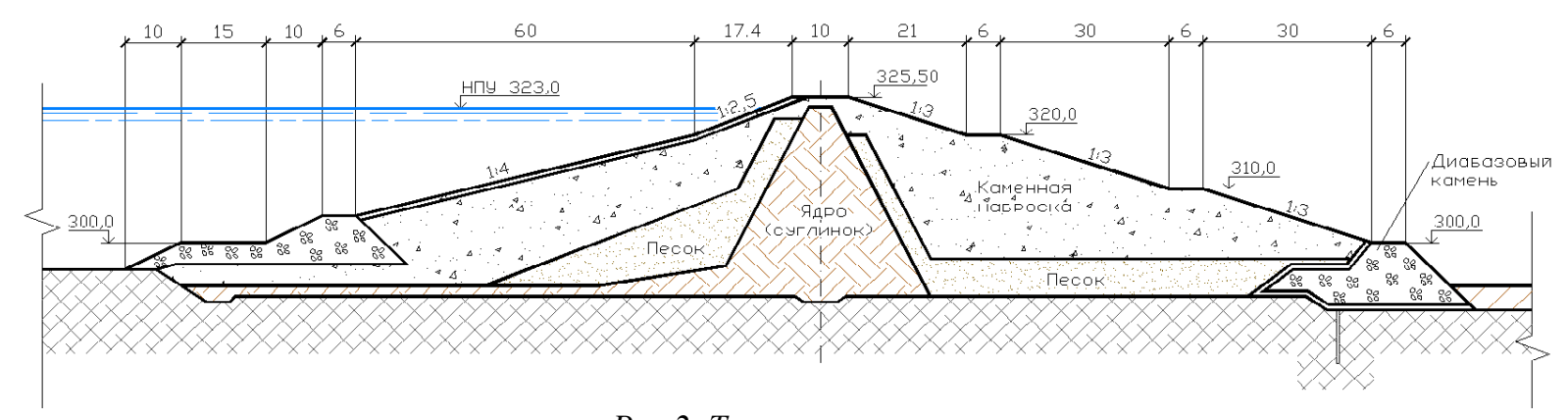

Рис.2. Типовое сечение плотиньл.

В настоящее время одной из основанных проблем эксплуатации накопителя минерализованных вод является фильтрация в основании левого крыла плотины. Близрасположенные к плотине выходы воды отмечаются в левобережной части 
нижнего бьефа. Зоны фильтрационных потоков в нижнем бьефе прослеживаются по выходам воды с высокой минерализацией (рис.3) [4].

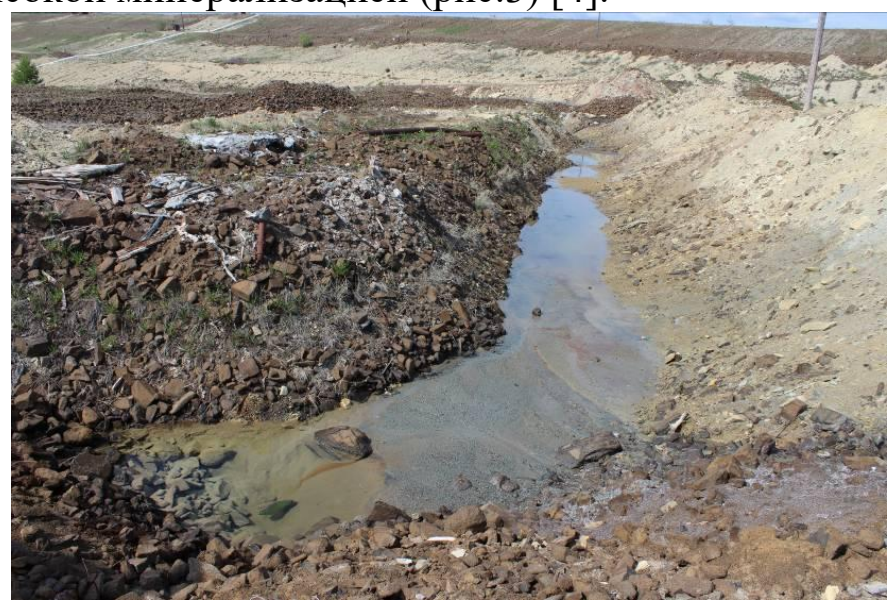

Рис. 3. Выход фильтрата в левобережной части плотин со стороны нижнего бьефа [4].

Для решения проблемы предлагается следующая инновационная система для обеспечения статической и фильтрационной устойчивости плотин в криолитозоне. На рис.4 показана принципиальная технологическая схема системы охлаждения и замораживания грунтов мерзлого противофильтрационного устройства плотины с использованием в качестве криогенного флюида естественного криопэга.

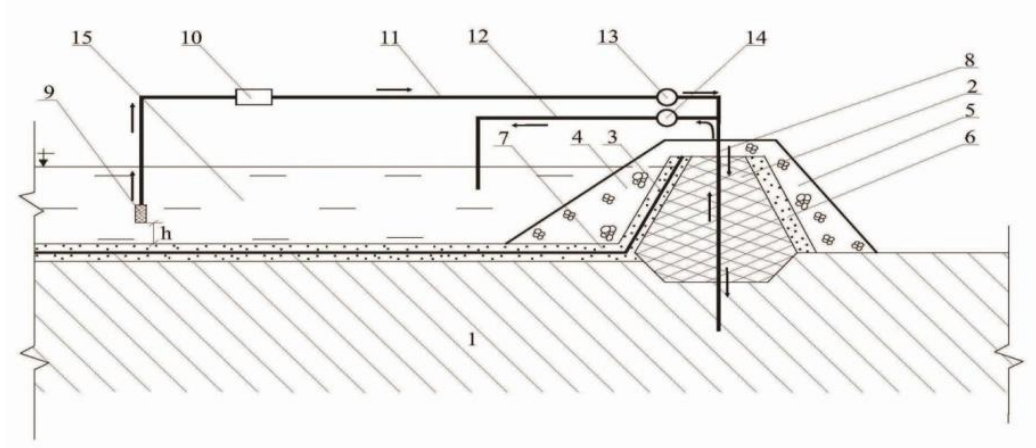

Рисунок 4. Принциииальная схема системы для охлаждения и замораживания грунта мерзлого противофильтрационного устройства плотины [11].

1 - многолетнемерзлое основание; 2 - мерзлое противофильтрационное ядро из суглинка; 3 геосинтетическийсолезащитныйэкран переходящий в понур; 4 и 5 - верховая и низовая упорные призмы из дисперсного грунта или каменной наброски; 6 и 7 - переходные зонь из песка; 8 - замораживающее устройство; 9 - рассолозаборник; 10 - насос; 11, 12 - подающий и отводящчий рассолопроводы; 13, 14 -

подводящий и отводящий коллектора; 15 - рассолохранилище естественных природных рассолов.

Грунтовая плотина возводится на многолетнемерзлом основании 1 и содержит мерзлое противофильтрационное ядро из суглинка 2; геосинтетическийсолезащитный экран 3; верховую и низовую упорные призмы из дисперсного грунта или каменной наброски 4 и 5; переходные зоны из песка 6 и 7; замораживающее устройство 8, переходящий в понур. Противофильтрационное ядро 2 отсыпается из грунта, увлажненного пресной водой до состояния полной влагоемкости.

Замораживающая система содержит следующие конструктивные элементы: замораживающее устройство 8; рассолозаборник 9; насос 10; подающий 11 и отводящий 12 рассолопроводы; подводящий 13 и отводящий 14 коллектора; рассолохранилище естественных природных рассолов 15 . 
Со стороны верхнего бьефа на откос ядра и в основании верховой упорной призмы в виде понура плотины по переходному слою из песка 7 уложен геосинтетический экран 3 (типа HDPE). Со стороны нижнего бьефа к противофильтрационному экрану 3 примыкает льдогрунтовая мерзлотная завеса, которая создается посредством колонок замораживающей системы 8 и герметически присоединена к экрану в результате смерзания.

Предложенная технологическая схема с использованием в качестве криогенного флюида естественного криопэга, позволит повысить надежность плотины (фильтрационную и статическую устойчивость) за счет эффективности круглогодичной работы замораживающей системы, образующих мерзлую противофильтрационной завесу в теле и основании, а использование геосинтетического экрана с понуром, обеспечивает дополнительную фильтрационную, в том числе солезащитную, устойчивость сооружения.

Технический результат достигается за счет использования рассолохранилища, как природной замораживающей машины, обеспечивающей формирование и длительное существование рассолов с низкими отрицательными температурами, используемые для поддержания тела и основания плотины в мерзлом состоянии.

Новым в предложенной технологической схеме является то, что в циркуляционном контуре охлаждения используется природные растворы, низкие отрицательные температуры в которых формируются за счет теплообмена рассолохранилища с окружающей средой.

\section{Заключение}

В настоящее время криогенные ресурсы, как часть природного ресурса, приобрели глобальный характер. Постоянно разрабатываются новые инновационные технические средства по рациональному их использованию и охране окружающей среды. Разработанная схема системы с использованием криопэгов для охлаждения, понижения температуры и замораживания грунтов грунтовых плотин в криолитозоне является инновационной разработкой и имеет хорошие перспективы.

$$
* * *
$$

1. Алексеев В.Р. Притяжение мерзлой земли / В.Р. Алексеев; отв. ред. В.В. Шепелёв; Рос.акад. наук, Сиб. отд-ние, Институт мерзлотоведения. - Новосибирск: Академическое изд-во «Гео», 2016. - 538 c.

2. Алексеев С.В., Вахрамеев А.Г., Коцупало Н.П., Рябцев А.Д. Промышленные рассолы Сибирской платформы: гидрогеология, бурение и добыча, переработка, утилизация / Алексеев С.В., Вахрамеев А.Г., Коцупало Н.П., Рябцев А.Д. - Иркутск: Изд-во «Географ», 2014. - 162 с.

3. Большая Советская энциклопедия. 3-е издание. Т. 20. М. Изд-во «Советская энциклопедия». - 1975.c.593-595.

4. Великин С.А. Геофизический мониторинг гидротехнических сооружений в криолитозоне на примере накопителя минерализованных вод Тымтайдах. Инженерные изыскания. М., 2006, №2, - с. $52-59$.

5. Кононова, Р. С. Криопэги - отрицательные температуры воды земли / Р. С. Кононова, Я. В. Неизвестнов, Н. И. Толстихин, О. Н. Толстихин // Мерзлотные исследования. - М.: Изд-во Моск. гос. ун-та, 1971. - Вып. ХІ. - С. 75-88.

6. Мельников В.П. Актуальность ресурсного подхода в криологии (приветственная речь на открытии конференции «Криосфера нефтегазовых провинций».Тюмень, 2004). Криосфера Земли. Т.IX, № 1. 2005. - c. 3-6.

7. Реймерс Н.Ф. Природопользование: Словарь-справочник. М., Мысль. - 1990. - 631с.

8. Толстихин Н.И. Криофера и криопеги // Изв. вузов. Геология и разведка. - 1982. - № 3. - c. 115-117.

9. Чжан Р.В. К вопросу использования криопэгов как криогенного ресурса криолитозоны при строительстве и эксплуатации сооружений // Фундаментальные исследования. - 2017. - № 5. - С. 98-104.

10. Чжан Р.В., Шестернев Д.М., Кузьмин Г.П., Великин С.А., Чжан А.А. Система для охлаждения и замораживания грунта. Патент на изобретение № 2634765. Заявка № 2016137039. Опубликовано: 03.11. 2017 Бюл. № 31.

11. Чжан Р.В., Шестернев Д.М., Великин С.А., Чжан А.А. Грунтовая плотина в зоне вечной мерзлоты. Заявка № 2017108228/13 (014394), заявлена 14.03.2017. 